\title{
A Systematic Evaluation of Literature on Internet of Things (IoT) and Smart Technologies with Multiple Dimensions
}

\author{
Inderpreet Kaur*, Kamaljit Singh Saini \\ Chandigarh University, Gharuan, CGC, Landran, Punjab-140307, India \\ E-mail: cecm.bca.ik@gmail.com*,kamaljit.cse@cumail.in
}

\section{ARTICLE INFORMATION}

Received: June 26, 2020

Revised: July 09, 2020

Accepted: July 11, 2020

Published online: July 31, 2020

\section{Keywords:}

Internet of things, Smart devices, Internet of everything, Cloud, Systematic literature review

\begin{abstract}
The advent of state of the art advanced technologies is necessitated by the ever-increasing onset and infiltration of our lives by the smart devices and gadgets for providing an array of services. The conventional methods and techniques already becoming obsolete and the consistent and persistent demand for provision of high end services with a greater degree of accuracy by various sectors, paves the way for collaboration of smart technologies such as Internet of things, Internet of everything, Internet of Vehicles etc. with the smart gadgets and devices. This systematic review tries to explore the avenues for research and multiple streaming of segments by the analysis of allied smart systems comprising of smart devices and multi-dimensional IoT, IoE, IoV etc.
\end{abstract}

DOI: $10.15415 /$ jtmge. 2020.111001

\section{Introduction}

With the changing times, even the IoT has evolved and transformed itself to IoE, (Shilpa et al., 2019) or IoX, which means Internet of Everything and has also been referred to in this research work. Its worldwide acceptance and efficient and convenient collaboration in the field of automation involving various disciplines be it engineering, corporate, social or personal, makes IoT one of the most sought after areas of research (as shown Figure 1). For trouble free inter -device communication, various sensor based systems and technologies are employed. (Al-Fuqaha et al., 2015; Botta $e t$ al., 2016; Islam et al., 2015 \& Sicari et al., 2015).

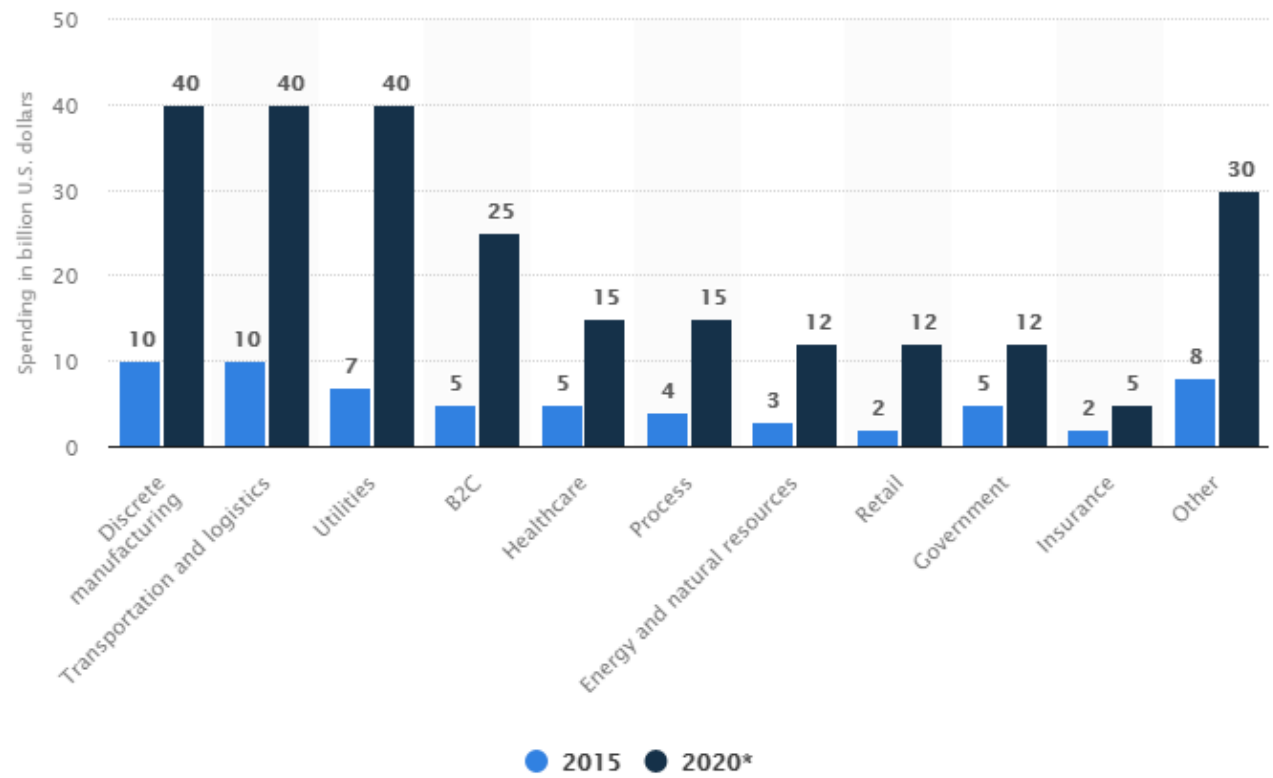

Figure 1: The elevating market (Billion US Dollars) of internet of things worldwide

Source: Statista, statistical research portal 


\subsection{IoT and Internet 4.0}

IoT based technology makes possible the integration of whole new idea of Internet 4.0 integrate smart manufacturing, in which process of data collection and data processing is done as accurately as possible by employing suitable sensors based systems. (Whitmore et al., 2015 \& Li, S. et al., 2015).

\subsection{Need of Decentralization in IoT}

The issue of efficient and trouble free working of smart devices deployed in Government and Corporate sector related Applications/Services is satisfactorily addressed by integrating decentralized applications.

dApp (Decentralized Application) thwarts any attempt to hijack the system as it involves the execution of software application on distributed multiple channels. Wheras, all the data is at stake, if someone hacks into the centralized servers. To overcome this threat, dApp is put into practice which makes it possible to maximize and replicate the transaction threads. In order to make dApp safer and user friendly, smart contracts are incorporated with dApp, which makes Dynamic Token sharing as a mandatory feature/step while completing the transaction. Not only does this smart contract based dApp enhance the security of transactions, but also makes it possible for people hailing from different countries with different languages to make transactions conveniently anywhere in the world. (Xu, J. 2020)

\section{Systematic Review Methods}

The review methods in the methodical aspects are having diversified key points with the direct addressing to the IoT based technologies. The review is done after extraction of assorted manuscripts and the research articles from multiple sources including Web of Science and related high citation sources of research. (Souri et al., 2019)

\section{Research Planning}

Following are the research questions and the key concerns which have been extracted from the literature and research portals, so that multi-dimensional analysis of the research in IoT and related domains can be done. (Brous et al., 2020)

RQ1: Which are the recent trends and technologies in the allied domains?

RQ2: Which are the influencing factors with the IoT and associated streams?

RQ3: Which sensor technologies are directly associated with the IoT?

RQ4: Which key points are mandatory to be analyzed with Internet of $\mathrm{X}$ (IoX)? Here $\mathrm{X}$ refers to Things, Objects, Clouds, Everything
RQ5: What are the open issues for IoT communication strategies?

Table 1: Adoption criteria for studies

\begin{tabular}{|l|l|}
\hline \multicolumn{2}{|c|}{ Adoption Criteria for the Studies } \\
\hline Factors & $\begin{array}{l}\text { Manuscript paper studies relevant to } \\
\text { Adoption Trends and Technologies, } \\
\text { Recent Protocols and Paradigms, } \\
\text { Creativity and Integration Panels with } \\
\text { the advanced approaches }\end{array}$ \\
\hline Exclusion & $\begin{array}{l}\text { Not having sufficient results and } \\
\text { ambiguous outcomes, Integration } \\
\text { with the non relevant datasets, studies } \\
\text { published before 2015 }\end{array}$ \\
\hline Quality & $\begin{array}{l}\text { Manuscripts having results with } \\
\text { enormous parameters and research } \\
\text { issues, Manuscripts having results with } \\
\text { multiple outcomes/results }\end{array}$ \\
\hline
\end{tabular}

Usually, an adoption criterion is determined after the research planning questions. Hence, Table 1 shows the adoption criteria used for selecting the manuscripts. In this table, each manuscript has been analyzed using different factors like title, results, abstract and conclusions. (Brous et al., 2020)

Table 2: Thematic types

\begin{tabular}{|c|c|}
\hline Articles & $\begin{array}{c}\text { Taxonomy of } \\
\text { Theme and } \\
\text { Coverage Patterns }\end{array}$ \\
\hline $\begin{array}{l}\text { (Shilpa et al., 2019; Al-Fuqaha } \\
\text { et al., 2015; Botta et al., 2016; } \\
\text { Islam et al., 2015; Sicari et al., } \\
\text { 2015; Whitmore et al., } 2015 ; \mathrm{Li} \text {, } \\
\text { S. et al., 2015; Xu, J et al., 2020; } \\
\text { Souri et al., 2019; Brous et al., } \\
\text { 2020; Granjal et al., } 2015 \text { and } \\
\text { Strohbach et al., 2015). }\end{array}$ & $\begin{array}{c}\text { IoT, Pervasive } \\
\text { Computing and } \\
\text { Smart Technologies }\end{array}$ \\
\hline $\begin{array}{l}\text { (Cheng et al., 2018; Araújo et } \\
\text { al., 2017; Hernández-Vega et } \\
\text { al., 2018; Keung et al., 2018; } \\
\text { Desikan et al., 2018; Bounceur } \\
\text { et al., 2017; Sanchez-Gomez et } \\
\text { al., 2017; Tabatabai et al., 2017; } \\
\text { Ouerhani et al., 2016; Corici et } \\
\text { al., 2016; Anagnostopoulos et } \\
\text { al., 2015; Barriga et al., 2016; } \\
\text { Govoni et al., 2016; Liu et al., } \\
\text { 2017; Silva et al., 2015; Sanchez } \\
\text { et al., 2014; Memos et al., 2018; } \\
\text { Balid et al., 2017; Masek et al., } \\
\text { 2016; Hu, L. et al., 2018; Badii et } \\
\text { al., 2019). }\end{array}$ & $\begin{array}{c}\text { IoT with Social } \\
\text { Applications and } \\
\text { Implementations in } \\
\text { E-Governance }\end{array}$ \\
\hline
\end{tabular}




\begin{tabular}{|l|c|}
\hline (Badii et al., 2018; Masek et al., & Traffic and Smart \\
2016; Misbahuddin et al., 2015; & Transportation \\
Sivanathan et al., 2017; Park et & \\
al., 2018; Nesi et al., 2018; Putra & \\
et al., 2018; Uzairue et al., 2018; & \\
Taha, 2018; Balid et al., 2017; & \\
Slamet et al., 2017; Malagund et & \\
al., 2016; Suzuki, 2017). & \\
\hline (Masmoudi et al., 2017; Bibri, & Sustainable \\
S. E. et al., 2018; Shah, J. et al., & Energy, Power \\
2016; Hernández-Vega et al., & and Environment \\
2018; Binsy et al., 2019; & Monitoring \\
Duangsuwan et al., 2018). & \\
& \\
\hline (Rocher et al., 2018; Miraz et & Internet of \\
al., 2015; Clarke, R. Y., 2013; & Everything (IoE) \\
Abdelwahab et al., 2014; & and Nano-Things \\
Abdelwahab et al., 2014; & \\
Bojanova et al., 2014; Naranjo et & \\
al., 2018; Zielinski, 2015). & \\
& \\
\hline
\end{tabular}

\begin{tabular}{|l|c|}
\hline Aazam et al., 2016; Abbasi- & $\begin{array}{c}\text { Telemedicine / } \\
\text { Moghadam et al., 2016; }\end{array}$ \\
Ahmart Healthcare \\
et al., 2017; Baker et al., 2018; & \\
Bali, S., 2018; Chau et al., 2002; & \\
Dahri et al., 2017; Fang, J. L et & \\
al., 2016; LeMoyne et al., 2016; & \\
Ly BA et al., 2017; Martin et al., & \\
2019; Mihuba et al., 2019; Paul & \\
et al., 1999; Perednia et al., 1995; & \\
Pillai CP et al., 2016; Raison & \\
et al., 2015; Wan Ahmad et al., & \\
2017; Yeo KJ. et al., 2017) & \\
\hline
\end{tabular}

\section{Execution Plan}

The execution plan contains five steps: (i) Search manuscripts from various portals; (ii) Repeated manuscripts are excluded; (iii) Select manuscripts on pre-defined criteria; (iv) Data extraction and quality assessment; (v) Meta analysis (Souri et al., 2019 and Brous et al., 2020). Furthermore, this manuscript used the following this manuscript used the following electronic databases to find the papers (as shown in Figure 2).

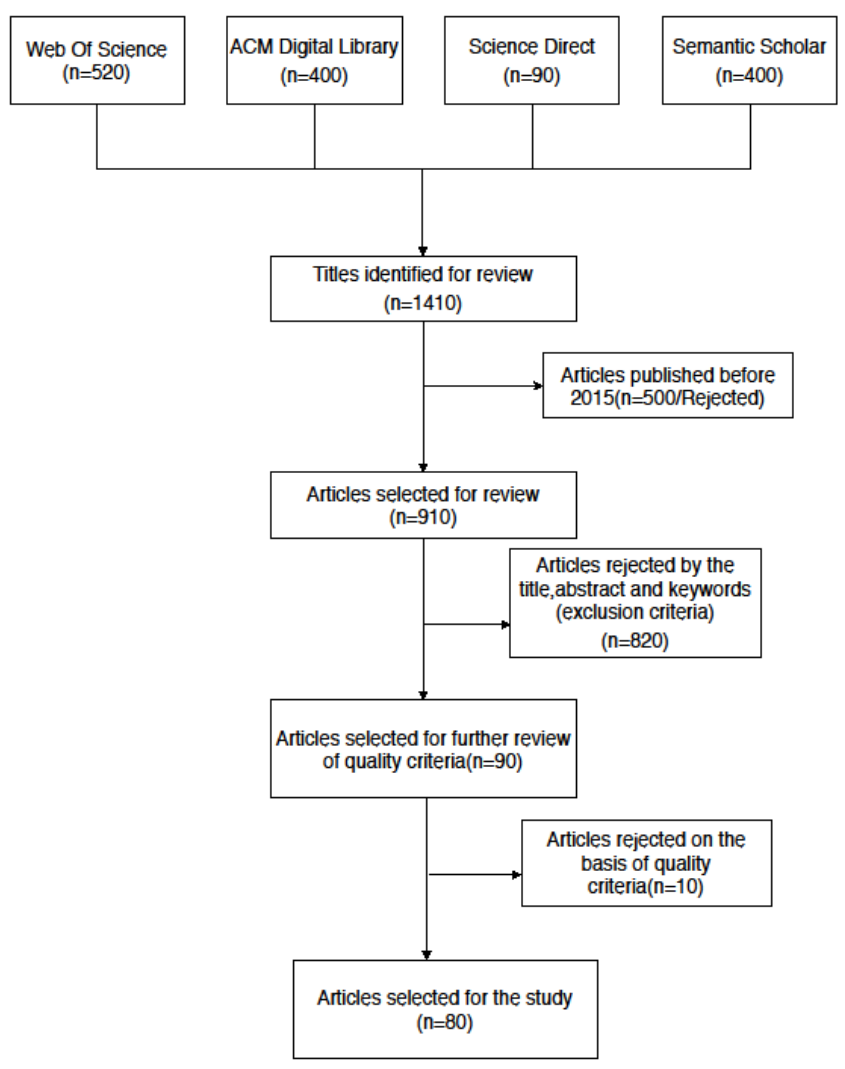

Figure 2: Systematic review research flow 
(i) Web of Science: webofknowledge.com

(ii) ACM Digital Library: https://dl.acm.org/

(iii) Science Direct: https://www.sciencedirect.com/

(iv) Semantic Scholar: https://www.semanticscholar.org/

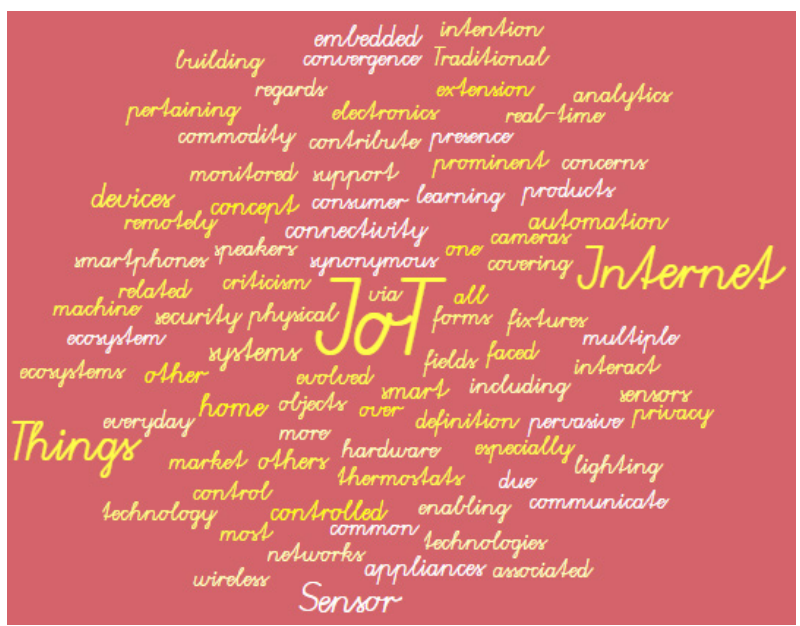

Figure 3: Word cloud formation

Following is the integration of word cloud from the assorted manuscripts and found that there are huge elevations and association of the IoT based technologies in the manuscripts focusing on the sensor technologies (as shown in Figure 3).

\section{Results}

This methodical analysis of the research manuscripts is having the multiple dimensions and research questions which are addressed henceforth with the analytics patterns.

RQ1: Which are the recent trends and technologies in the allied domains?

The recent trends are classified into six themes (Table $3 \& 4$ ): IoT, Pervasive Computing and Smart Technologies; IoT with Social Applications and Implementations in E-Governance; Traffic and Smart Transportation; Sustainable Energy, Power and Environment Monitoring; Internet of Everything (IoE) and Nano-Things; Telemedicine / Smart Healthcare.

(i) Pervasive Computing and Smart Technologies: Pervasive computing is also referred as ubiquitous computing or invisible computing that means technology taking the back stage. IoT may make modern life more convenient and connects the physical world to the internet. Some of the common examples of Ubiquitous IoT devices are health trackers, smart thermostats etc. (Granjal, 2015 and Strohbach, 2015)

(ii) IoT with Social Applications and Implementations in E-Governance (Electronic-Governance): A new paradigm social IoT (SIoT) means a social relationships between the objects like humans beings, the main features of Slot are: (i) it is navigable; (ii) a trustworthiness needs to be present between devices (similar to friends on facebook). To provide government services at the door steps of citizens is the main purpose of e-governance.
The implementation process of e-governance includes the following: (i) GBPR (Government Business Process Re-engineering) - it changes to the already existing procedure to make it more efficient with the help of their services like, online tracking process. Eg: online application submission requesting for Birth certificate; (ii) EB (Electronic database) - It involves the digitizing of data that is involved with the government such as government records, tenders etc. (Cheng et al., 2018 and Hernández-Vega et al., 2018)

(iii) Traffic and Smart Transportation: Mobility and intelligent transportation systems (ITS) takes advantage of technologies like IoT and big data analytics to manage traffic and mobility in smart cities. It provides improved interfaces that enhance transport infrastructure and transport services. An ITS includes: (i) Creating different interconnected transport systems integrates communication between devices and vehicles; (ii) It provides the direct access of real time information about transport condition (Masek et al., 2016; Sivanathan et al., 2017 and Park et al., 2018).

(iv) Sustainable Energy, Power and Environment Monitoring: For renewable energy sector, IoT is one of the main key components in the next growth stage. Smart energy solutions are surely a better approach than the already existing non-renewable resource that produces harmful gases. An application of IoT alleviates many challenges that are limiting the acceptance of renewables. Some of the IoT applications in renewable energy are: (i) Smart grids for enhanced renewable implementation; (ii) Automation to improve the overall production (Masmoudi et al., 2017 and Bibri, 2018).

(v) Internet of Everything (IoE) and Nano-Things: IoT is composed of things only but the IoE is built on four pillars (data, people, process and things). IoE has the potential to extract real time data from million and billons of sensors that are connected to it. The IoT is being extended by the implementation of Internet of Nano Things. The different functional task like sensing or actuation is done by nano machine in IoNT (Miraz et al., 2015; Clarke, 2013 and Abdelwahab et al., 2014).

(vi) Telemedicine / Smart Healthcare IoT has transformed the arena of healthcare by yielding continuous health monitoring services very important feature of IoT in smart devices to connect the different health apps for tracking the patients health and to ensure their compliance. Telemedicine is remote monitoring of the patients who are unable to visit doctors due to the age, distance or other unavoidable reasons etc., so this technology provides virtual healthcare assistance helps people located in remote areas or the ones who are unable to visit the doctors and hospitals due to factors like distance, age, or busy lifestyle. (Aniza et al., 2017; Baker et al., 2018; Chau et al., 2002 and Dahri et al., 2017). 
Table 3: Recent trends and themes in IOT, Pervasive Computing \& Smart Technology

\begin{tabular}{|c|l|c|}
\hline$\#$ & Theme and Key Aspects & Manuscripts \\
\hline 1 & $\begin{array}{l}\text { IoT, Pervasive Computing and } \\
\text { Smart Technologies }\end{array}$ & 12 \\
\hline 2 & $\begin{array}{l}\text { IoT with Social Applications } \\
\text { and Implementations in } \\
\text { E-Governance }\end{array}$ & 21 \\
\hline 3 & $\begin{array}{l}\text { Traffic and Smart } \\
\text { Transportation }\end{array}$ & 13 \\
\hline 4 & $\begin{array}{l}\text { Sustainable Energy, Power and } \\
\text { Environment Monitoring }\end{array}$ & 6 \\
\hline 5 & $\begin{array}{l}\text { Internet of Everything (IoE) } \\
\text { and Nano-Things }\end{array}$ & 20 \\
\hline 6 & $\begin{array}{l}\text { Telemedicine / Smart } \\
\text { Healthcare }\end{array}$ & $\mathbf{8 0}$ \\
\hline & \multicolumn{2}{|c}{ Cumulative } \\
\hline
\end{tabular}

RQ2: Which are the influencing factors with the IoT and associated streams?

Table 4: IoT influencing factors with associated streams

\begin{tabular}{|c|l|c|}
\hline$\#$ & \multicolumn{1}{|c|}{ Influencing Factors } & Manuscripts \\
\hline 1 & $\begin{array}{l}\text { Standardization of the } \\
\text { protocols and approaches with } \\
\text { the cavernous techniques for } \\
\text { accuracy and minimum delay }\end{array}$ & 2 \\
\hline 2 & Higher degree of throughput & 3 \\
\hline 3 & System Architecture & 8 \\
\hline 4 & Interoperability and Integration & 3 \\
\hline 5 & $\begin{array}{l}\text { Availability and Integration } \\
\text { with other networks }\end{array}$ & 4 \\
\hline
\end{tabular}

\begin{tabular}{|c|l|c|}
\hline 6 & $\begin{array}{l}\text { Availability and Reliability } \\
\text { Factors }\end{array}$ & 6 \\
\hline 7 & $\begin{array}{l}\text { Data Storage, Big Data } \\
\text { Handling and Unstructured } \\
\text { Processing }\end{array}$ & 5 \\
\hline 8 & $\begin{array}{l}\text { Self Management and Fault } \\
\text { Tolerance }\end{array}$ & 8 \\
\hline 9 & Self Configuration & 4 \\
\hline 10 & $\begin{array}{l}\text { Performance Points and Quality } \\
\text { of Service (QoS) }\end{array}$ & 3 \\
\hline 11 & $\begin{array}{l}\text { Identification and Unique } \\
\text { Addressing }\end{array}$ & 2 \\
\hline 12 & Power and Energy Optimization & 3 \\
\hline 13 & Security, Integrity and Privacy & 4 \\
\hline 14 & $\begin{array}{l}\text { Environment Issues and } \\
\text { Sustainable Energy }\end{array}$ & \\
\hline
\end{tabular}

RQ3: Which sensor technologies are directly associated with the IoT?

(i) Proximity Sensor (used in retail industry to detect motion and correlation between the customer and product)

(ii) Pressure Sensor (used for the maintenance of water systems and heating systems)

(iii) Gas Sensor (used to detect the quality of air and level of different gases present in the air)

(iv) Water quality Sensor(used for monitor the quality of water for different purposes like $\mathrm{pH}$ sensor, Chlorine Residual Sensor)

(v) Humidity Sensor (used to detect amount of water vapour in an atmosphere of air)

(vi) Motion Detection Sensors (used to detect the physical motion or movement of any object or human beings)

RQ4: Which key points are mandatory to be analyzed with Internet of $\mathrm{X}$ (IoX)? Here $\mathrm{X}$ refers to Things, Objects, Clouds, Everything

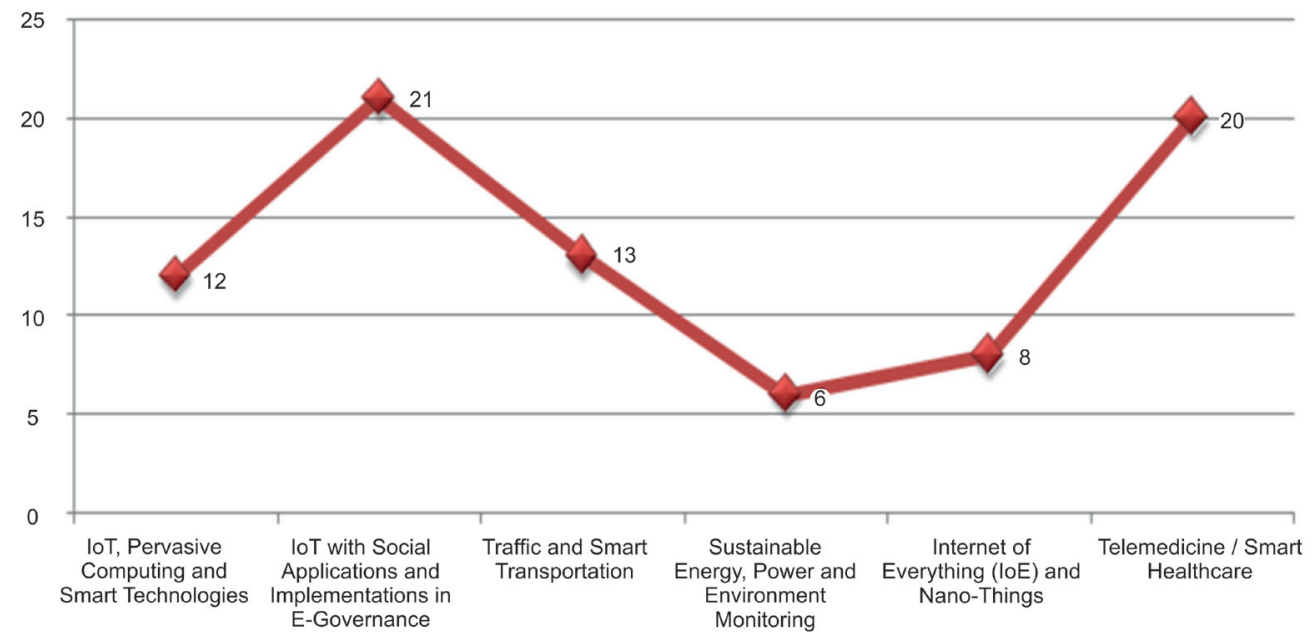

Figure 4: Coverage of themes 
Identification of Motes, Design and Architecture, Networking, Standardization.

Identification of Motes: A mote (short form for Remote) acts as a remote sensor is a wireless transceiver that has the ability to log onto a network from a remote or distant location. Motes in IoT are IP-enabled and thus are provided with an IP addresses (6lowPAN) allowing them to interact with remote nodes in an end to end way. Contiki OS implements a lightweight IP stack into classical WSN nodes e.g. MICAz, Tmote etc. Crossbow MICAz can be widely used in monitoring as well as security purposes. The MICAz software consists of two software components- Moteworks and Moteview. Mote-Works based on TinyOS operating system, it is being used for the development of custom sensor applications. Mote-view it works as intermediate between users and the network. Mote-view is used and has the capability of displaying and analyzing the data collected by the motes.

Design and Architecture: The architecture of IoT contains very large number of elements like protocols, actuators, sensors, cloud services and different layers. The design architecture of IoT has four different stages: (i) IoT network protocols (actuators and sensors); (ii) Data acquisition systems and internet gateways; (iii) Analytics and pre-processing; (iv) Analysis, management and storage of data.

Networking: WSN (Wireless Sensor Network) is a collection of distributed sensors that monitors environmental conditions like pressure, sound and temperature. WSN plays an important role in IoT by using communication technology. For the connectivity requirements for Io $\mathrm{T}$, a single technology cannot meet all the requirements like range, power, size and cost etc. If your IoT network is local and limited to M2M (Machine to Machine) then 6LoWPAN, DASH7, Wireless M-Bus, Z-Wave and SA100 are the good candidates. But if you want to transfer data over internet then IPV6 (Internet Protocol Version 6) is the right choice.

Standardization: IoT standardization is an important key to reduce the cost of data; to reduce the cost of manufacturing individual components; to reduce transport cost; to reduce the gaps between protocols. For instance IoT protocols are Bluetooth, $\mathrm{WiFi}$, COAP (Constrained Application Protocol), Lora WAN (Long Ranged Wide Area Network) etc.

RQ5: What are the open issues for IoT communication strategies?

(i) Privacy and Security: In the realization of IoT communication, the most important challenges are its privacy and security. The main challenges from the security point of view are authentication, distributed denial of service (DDOS), trust and access control. (ii) Interoperability: It is a important feature for communication between smart devices, Io $\mathrm{T}$ applications and cloud providers. The main challenges in this area are scalable architecture to interact with data center and smart things.

(iii Trust and access control: It is an important key challenge to increase. For safe data delivery, trust management can be very effective in smart things and IoT. Moreover; can be an influential factor between smart devices and IoT for trustable communication.

(iv) Energy consumption: The various IoT devices such as sensors, mobile agents, and wireless technology are physically interacted with the IoT applications. These IoT applications have more energy efficient when we compare these with centralized topologies. Moreover, achieving industry 4.0 is not an easy as it faces many difficulties and challenges.eg. technological, scientific and economical.

\section{Final Considerations}

From the voluminous and diversified literature analysis, it has been found that the factors for comparing quality of service with the performance parameters are the key points in the research domain of IoT. The analytics from the research portals and manuscripts show that the performance and availability of the sensor technologies are highly addressed with the overall effectiveness so that the real and efficiency-aware adoption of IoT can be done for multiple applications in the real world.

\section{References}

Aazam, M., \& Huh, E. N. (2016). Fog Computing: The Cloud-iot $\backslash$ ioe Middleware Paradigm. IEEE Potentials, 35(3), 40-44.

https://doi.org/10.1109/MPOT.2015.2456213

Abbasi-Moghadam, D., Hotkani, S. M. H. N., \& Abolghasemi, M. (2016). Store and Forward Communication Payload Design for LEO Satellite Systems. Majlesi Journal of Electrical Engineering, 10(3), 7-17.

Abdelwahab, S., Hamdaoui, B., Guizani, M. \& Rayes, A. (2014). Enabling Smart Cloud Services through Remote Sensing: An Internet of Everything Enabler. IEEE Internet of Things Journal, 1(3), 276-288. https://doi.org/10.1109/JIOT.2014.2325071

Ahmadi H, Nilashi M, Almaee A, Soltani M, Zare M, Sangar AB, et al. (2016). Multi-level Model for the Adoption of Hospital Information System: A Case on Malaysia. Journal of Soft Computing and Decision Support Systems, 3(1), 61-74.

Al-Fuqaha, A., Guizani, M., Mohammadi, M., Aledhari, M. \& Ayyash, M. (2015). Internet of Things: A Survey on Enabling Technologies, Protocols, and Applications. IEEE Communications Surveys \& Tutorials, 17(4), 2347-2376.

https://doi.org/10.1109/COMST.2015.2444095 
Anagnostopoulos, T., Zaslavsky, A., Georgiou, S. \& Khoruzhnikov, S. (2015). High Capacity Trucks Serving as Mobile Depots for Waste Collection in IoT-enabled Smart Cities. In Internet of Things, Smart Spaces, and Next Generation Networks and Systems, 80-94. Springer, Cham.

Aniza I, Baharin K, Idris IB, Jamil AT, Khalib AL, et al. (2017), Short Messaging Service (SMS) for Rural Outpatient Department in Malaysia: Is It a Suitable Practice to Increase Patient's Satisfaction and Quality of Care?. International Medical Journal, 24(4), 333-336.

Araújo, A., Kalebe, R., Girão, G., Gonçalves, K., Melo, A., \& Neto, B. (2017). IoT-based Smart Parking for Smart Cities. In 2017 IEEE First Summer School on Smart Cities (S3C), 31-36. IEEE.

https://doi.org/10.1109/S3C.2017.8501376

Badii, C., Belay, E. G., Bellini, P., Marazzini, M., Mesiti, M. et al. (2018). Snap4City: A Scalable IOT/IOE Platform for Developing Smart City Applications. In 2018 IEEE SmartWorld, Ubiquitous Intelligence \& Computing, Advanced \& Trusted Computing; Scalable Computing \& Communications, Cloud \& Big Data Computing, Internet of People and Smart City Innovation, 2109-2116. IEEE.

Badii, C., Bellini, P., Difino, A. \& Nesi, P. (2019). Sii-Mobility: An IoT/IoE Architecture to Enhance Smart City Mobility and Transportation Services. Sensors, 19(1), 1.

https://doi.org/10.3390/s19010001

Baker, J. \& Stanley, A. (2018). Telemedicine Technology: A Review of Services, Equipment, and other Aspects. Current Allergy and Asthma Reports, 18(11), 60.

Bali, S. (2018). Enhancing the Reach of Health Care through Telemedicine: Status and New Possibilities in Developing Countries. In Health Care Delivery and Clinical Science: Concepts, Methodologies, Tools, and Applications, 1382-1397. IGI Global.

https://doi.org/10.4018/978-1-5225-3926-1.ch069

Balid, W. \& Refai, H. H. (2017). On the Development of Self-powered IoT Sensor for Real-time Traffic Monitoring in Smart Cities. In 2017 IEEE SENSORS, 1-3. IEEE.

https://doi.org/10.1109/ICSENS.2017.8234157

Barriga, J. K. D., Romero, C. D. G., \& Molano, J. I. R. (2016). Proposal of a Standard Architecture of IoT for Smart Cities. In International Workshop on Learning Technology for Education Challenges, 77-89. Springer, Cham.

Bibri, S. E. (2018). The IoT for Smart Sustainable Cities of the Future: An Analytical Framework for Sensor-based Big Data Applications for Environmental Sustainability. Sustainable Cities and Society, 38, 230-253.

https://doi.org/10.1016/j.scs.2017.12.034

Binsy, M. S. \& Sampath, N. (2019). User Configurable and Portable Air Pollution Monitoring System for Smart Cities Using IoT. In International Conference on Computer Networks and Communication Technologies, 345-359. Springer, Singapore.

https://doi.org/10.1007/978-981-10-8681-6
Bojanova, I., Hurlburt, G. \& Voas, J. (2014). Imagineering An Internet of Anything, Computer, 47(6), 72-77.

Botta, A., De Donato, W., Persico, V., and Pescapé, A. (2016). Integration of Cloud Computing and Internet of Things: A Survey, Future Generation Computer Systems, 56, 684-700.

https://doi.org/10.1016/j.future.2015.09.021

Bounceur, A., Bezoui, M., Euler, R. \& Lalem, F. (2017). A Wait-before-starting Algorithm for Fast, Fault-tolerant and Low Energy Leader Election in WSNs dedicated to Smart-cities and IoT. In 2017 IEEE SENSORS, 1-3. IEEE.

https://doi.org/10.1109/ICSENS.2017.8234162

Brous, P., Janssen, M., \& Herder, P. (2020). The Dual Effects of the Internet of Things (IoT): A Systematic Review of the Benefits and Risks of IoT Adoption by Organizations. International Journal of Information Management, 51, 101952.

https://doi.org/10.1016/j.ijinfomgt.2019.05.008

Chau, P.Y. \& Hu, P.J.H. (2002). Investigating Healthcare Professionals' Decisions to Accept Telemedicine Technology: An Empirical Test of Competing Theories. Information \& Management, 39(4), 297-311. https://doi.org/10.1016/S0378-7206(01)00098-2

Cheng, B., Solmaz, G., Cirillo, F., Kovacs, E., Terasawa, K. \& Kitazawa, A. (2018). Fog Flow: Easy Programming of IoT Services Over Cloud and Edges for Smart Cities. IEEE Internet of Things Journal, 5(2), 696-707. https://doi.org/10.1109/JIOT.2017.2747214.

Clarke, R. Y. (2013). Smart Cities and the Internet of Everything: The Foundation for Delivering Nextgeneration Citizen Services. Alexandria, VA, Tech. Rep.

Corici, A., Steinke, R., Magedanz, T., Coetzee, L., Oosthuizen, D., Mkhize, B. \& Nehls, D. (2016). Towards Programmable and Scalable IoT Infrastructures for Smart Cities. In 2016 IEEE International Conference on Pervasive Computing and Communication Workshops (PerCom Workshops), 1-6. IEEE.

https://doi.org/10.1 109/PERCOMW.2016.7457132

Dahri, F. A., Soomro, R. A. \& Memon, Z. A. (2017). Design of Wearable Microstrip Yagi Array Antenna aimed for Telemedicine Applications. Academic Journal of Management Science (AJMS), 5(2), 45-52.

de la Torre Díez, I., Alonso, S. G., Hamrioui, S., LópezCoronado, M., \& Cruz, E. M. (2018). Systematic Review about QoS and QoE in Telemedicine and eHealth Services and Applications. Journal of Medical Systems, 42(10), 182.

https://doi.org/10.1007/s10916-018-1040-4

Desikan, K. S., Kotagi, V. J. \& Murthy, C. S. R. (2018). Smart at Right Price: A Cost Efficient Topology Construction for Fog Computing Enabled IoT Networks in Smart Cities. In 2018 IEEE 29th Annual International Symposium on Personal, Indoor and Mobile Radio Communications (PIMRC), 1-7. IEEE. https://doi.org/10.1109/PIMRC.2018.8580922 
Duangsuwan, S., Takarn, A. \& Jamjareegulgarn, P. (2018). A Development on Air Pollution Detection Sensors based on NB-IoT Network for Smart Cities. In 2018 18th International Symposium on Communications and Information Technologies (ISCIT), 313-317. IEEE.

https://doi.org/10.1109/ISCIT.2018.8587978

Fang, J. L., Collura, C.A., Johnson, R.V., Asay, G.F., Carey, W.A. et al. (2016). Emergency Video Telemedicine Consultation for Newborn Resuscitations: The Mayo Clinic experience. In Mayo Clinic Proceedings, 91(12), 1735-1743. Elsevier.

https://doi.org/10.1016/j.mayocp.2016.08.006

Govoni, M., Michaelis, J., Morelli, A., Suri, N. \& Tortonesi, M. (2016). Enabling Social and Locationaware IoT Applications in Smart Cities. In International Conference on Smart Objects and Technologies for Social Good, 305-314. Springer, Cham.

Granjal, J., Monteiro, E. \& Silva, J. S. (2015). Security for the Internet of Things: A Survey of Existing Protocols and Open Research Issues. IEEE Communications Surveys \& Tutorials, 17(3), 1294-1312.

https://doi.org/10.1109/COMST.2015.2388550

Hernández-Vega, J. I., Varela, E. R., Romero, N. H., Hernández-Santos, C., Cuevas, J. L. S. \& Gorham, D. G. P. (2018), Internet of Things (IoT) for Monitoring Air Pollutants with an Unmanned Aerial Vehicle (UAV) in a Smart City. In Smart Technology, 108-120. Springer, Cham.

https://doi.org/10.1007/978-3-319-73323-4_11

Hernández-Vega, J. I., Varela, E. R., Romero, N. H., Hernández-Santos, C. et al. (2018), Internet of Things (IoT) for Monitoring Air Pollutants with an Unmanned Aerial Vehicle (UAV) in a Smart City. In Smart Technology, 108-120. Springer, Cham.

Hu, L. \& Ni, Q. (2018). IoT-driven Automated Object Detection Algorithm for Urban Surveillance Systems in Smart Cities. IEEE Internet of Things Journal, 5(2), $747-754$

https://doi.org/10.1109/JIOT.2017.2705560

Islam, S. R., Kwak, D., Kabir, M. H., Hossain, M., \& Kwak, K. S. (2015). The Internet of Things for Healthcare: A Comprehensive Survey. IEEE Access, 3, 678-708. https://doi.org/10.1109/ACCESS.2015.2437951

Keung, K. L., Lee, C. K. M., Ng, K. K. H. \& Yeung, C. K. (2018). Smart City Application and Analysis: Realtime Urban Drainage Monitoring by IoT Sensors: A Case Study of Hong Kong. In 2018 IEEE International Conference on Industrial Engineering and Engineering Management (IEEM), 52 1-525. IEEE.

https://doi.org/10.1109/IEEM.2018.8607303

LeMoyne, R. \& Mastroianni, T. (2016). Telemedicine Perspectives for Wearable and Wireless Applications Serving the Domain of Neurorehabilitation and Movement Disorder Treatment. Telemedicine, SMGroup, Dover, Delaware, 1-10.
Li, S., Da Xu, L., \& Zhao, S. (2015). The Internet of Things: A Survey. Information Systems Frontiers, 17(2), 243-259.

Liu, Z., Wang, Y., Xu, Q. \& Yan, T. (2017). Study on Smart City Construction of Jiujiang based on IOT Technology. In IOP Conference Series: Earth and Environmental Science, 69(1), 012105. IOP Publishing.

Ly BA, Labonté R, Bourgeault I L, Niang M N (2017). The Individual and Contextual Determinants of the use of Telemedicine: A Descriptive Study of the Perceptions of Senegal's Physicians and Telemedicine Projects Panagers. PLoS One, 12(7), e0181070. https://doi.org/10.1371/journal.pone.0181070

Malagund, K. B., Mahalank, S. N. \& Bnakar, R. M. (2016). IoT Based Smart CityTtraffic Alert System Design. In 2016 International Conference on Computing Communication Control and automation, 1-6. IEEE. https://doi.org/10.1 109/ICCUBEA.2016.7860146

Martin, G., Khajuria, A., Arora, S., King, D., Ashrafian, H. \& Darzi, A. (2019). The Impact of Mobile Technology on Teamwork and Communication in Hospitals: A Systematic Review. Journal of the American Medical Informatics Association, 26(4), 339-355. https://doi.org/10.1093/jamia/ocy 175

Masek, P., Masek, J., Frantik, P., Fujdiak, R., Ometov, A. et al. (2016). A Harmonized Perspective on Transportation Management in Smart Cities: The Novel IoT-driven Environment for Road Traffic Modeling. Sensors, 16(11):1872.

https://doi.org/10.3390/s 16111872

Masmoudi, I., Elleuch, W., Wali, A. and Alimi, A. M. (2017). Smart Drivers' Guidance System Based on IoT Technologies for Smart Cities Application. In International Conference on Hybrid Artificial Intelligence Systems, 531-542. Springer, Cham.

https://doi.org/10.1007/978-3-319-59650-1_45

Memos, V. A., Psannis, K. E., Ishibashi, Y., Kim, B. G., \& Gupta, B. B. (2018). An Efficient Algorithm for Media-based Surveillance System (EAMSuS) in IoT Smart City Framework. Future Generation Computer Systems, 83, 619-628.

https://doi.org/10.1016/j.future.2017.04.039

Mihuba, G. G., Shundi, M. J., Bishoge, O. K. \& Nyangarika, A. M (2019). Design of Telemedicine System Based on Mobile Terminal. International Journal of Emerging Technologies in Engineering Research (IJETER), 7(1), 5-12.

Miraz, M. H., Ali, M., Excell, P. S. \& Picking, R. (2015). A Review on Internet of Things (IoT), Internet of Everything (IoE) and Internet of Nano Things (IoNT), In 2015 Internet Technologies and Applications (ITA), 219-224. IEEE. https://doi.org/10.1109/ITechA.2015.7317398

Misbahuddin, S., Zubairi, J. A., Saggaf, A., Basuni, J., Sulaiman, A. et al. (2015). IoT Based Dynamic Road 
Traffic Management for Smart Cities. In 2015 12th International Conference on High-capacity Optical Networks and Enabling/Emerging Technologies, 1-5. IEEE.

https://doi.org/10.1109/HONET.2015.7395434

Naranjo, P. G. V., Pooranian, Z., Shojafar, M., Conti, M. and Buyya, R. (2018). FOCAN: A Fog-Supported Smart City Network Architecture for Management of Applications in the Internet of Everything environments. Journal of Parallel and Distributed Computing, 132, 274-283.

https://doi.org/10.1016/j.jpdc.2018.07.003

Nesi, P., Badii, C. \& Difino, A. (2018). Sii-Mobility: an IOT/IOE Architecture to Enhance Smart City Services of Mobility and Transportation. Sensors, 19(1),1. https://doi.org/10.3390/s19010001

Ouerhani, N., Pazos, N., Aeberli, M. \& Muller, M. (2016). IoT-based Dynamic Street Light Control for Smart Cities use Cases. In 2016 International Symposium on Networks, Computers and Communications (ISNCC), 1-5. IEEE.

https://doi.org/10.1109/ISNCC.2016.7746112

Park, E., del Pobil, A., \& Kwon, S. (2018). The Role of Internet of Things(IoT) in Smart Cities: Technology Roadmap-oriented Approaches. Sustainability, 10(5), 1388. https://doi.org/10.3390/su 10051388

Paul, D.L., Pearlson, K.E. \& McDaniel, R.R. (1999). Assessing Technological Barriers to Telemedicine: Technology Management Implications. IEEE Transactions on Engineering Management, 46(3), 279288. https://doi.org/10.1109/17.775280

Perednia, D.A. \& Allen, A. (1995). Telemedicine Technology and Clinical Applications, Jama, 273(6), 483-488. https://doi.org/10.1001/jama.1995.03520300057037

Pillai CP, Yoshida Y, Lawrence PJ, Yamamoto E, Reyer JA, Hamajima N. (2016). Pediatric Cardiothoracic Program in Malaysia: A Study Based on the Outcome of the Program. Nagoya Journal of Medical Science, 78(1), 9.

Putra, A. S., \& Warnars, H. L. H. S. (2018). Intelligent Traffic Monitoring System (ITMS) for Smart City Based on IoT Monitoring. In 2018 Indonesian Association for Pattern Recognition International Conference, 161-165. IEEE.

https://doi.org/10.1109/INAPR.2018.8626855

Raison, N., Khan, M. S. \& Challacombe, B. (2015) "Telemedicine in Surgery: What are the Opportunities and Hurdles to Realising the Potential?", Current Urology Reports, 16(7), 43.

https://doi.org/10.1007/s 1 1934-015-0522-x

Rocher, J., Taha, M., Parra, L., \& Lloret, J. (2018). IoT Sensor to Detect Fraudulent Use of Dyed Fuels in Smart Cities. In 2018 Fifth International Conference on Internet of Things: Systems, Management and Security, 86-92. IEEE.

https://doi.org/10.1109/IoTSMS.2018.8554631
Sanchez, L., Muñoz, L., Galache, J. A., Sotres, P., Santana, J. R., Gutierrez, V. \& Pfisterer, D. (2014). Smart Santander: IoT Experimentation Over a Smart City Test bed. Computer Networks, 61, 217-238.

https://doi.org/10.1016/j.bjp.2013.12.020

Sanchez-Gomez, J., Sanchez-Iborra, R. \& Skarmeta, A. (2017). Transmission Technologies Comparison for IoT Communications in Smart-cities. In GLOBECOM 2017-2017 IEEE Global Communications Conference, 1-6. IEEE.

https://doi.org/10.1109/GLOCOM.2017.8254530

Shah, J., \& Mishra, B. (2016). IoT Enabled Environmental Monitoring System for Smart Cities. In 2016 International Conference on Internet of Things and Applications (IOTA), 383-388. IEEE.

https://doi.org/10.1109/IOTA.2016.7562757

Shilpa, A., Muneeswaran, V. \& Sherin, J. (2019). Exploring the Benefits of Sensors in Internet of Everything (IoE). In 2019 5th International Conference on Advanced Computing \& Communication Systems (ICACCS), 510514.

https://doi.org/10.1109/ICACCS.2019.8728530

Sicari, S., Rizzardi, A., Grieco, L. A., \& Coen-Porisini, A. (2015). Security, Privacy and Trust in Internet of Things: The Road Ahead. Computer Networks, 76,146164. https://doi.org/10.1016/j.comnet.2014.11.008

Silva, R., Silva, J. S., \& Boavida, F. (2015). A Symbiotic Resources Sharing IoT Platform in the Smart Cities Context. In 2015 IEEE Tenth International Conference on Intelligent Sensors, Sensor Networks and Information Processing (ISSNIP), 1-6. IEEE.

Sivanathan, A., Sherratt, D., Gharakheili, H. H., Radford, A., Wijenayake, C. et al. (2017). Characterizing and Classifying IoT Traffic in Smart Cities and Campuses. In 2017 IEEE Conference on Computer Communications Workshops, 559-564. IEEE.

https://doi.org/10.1109/INFCOMW.2017.8116438

Slamet, W., Made, K., Tubagus, P., Agus, S. \& Wiwoho, M. S. (2017). Internet of Things (IoT) as Green City Economic Development Smart Transportation System. In MATEC Web of Conferences, 138, p. 07015. EDP Sciences.

https://doi.org/10.1051/matecconf/201713807015

Souri, A., Hussien, A., Hoseyninezhad, M., and Norouzi, M. (2019). A Systematic Review of IoT Communication Strategies for an Efficient Smart Environment. Transactions on Emerging Telecommunications Technologies, e3736.

https://doi.org/10.1002/ett.3736

Strohbach, M., Ziekow, H., Gazis, V. and Akiva, N. (2015). Towards a Big Data Analytics Framework for IoT and Smart City Applications. In Modeling and Processing for Next-generation Big-data Technologies, $257-282$. Springer, Cham.

https://doi.org/10.1007/978-3-319-09177-8_11 
Suzuki, L. R. (2017). Smart Cities IoT: Enablers and Technology Road Map. In Smart City Networks, 167190. Springer, Cham.

Tabatabai, S., Mohammed, I., Al-Fuqaha, A. and Salahuddin, M. A. (2017). Managing a Cluster of IoT Brokers in Support of Smart City Applications. In 2017 IEEE 28th Annual International Symposium on Personal, Indoor, and Mobile Radio Communications (PIMRC), 1-6. IEEE.

https://doi.org/10.1109/PIMRC.2017.8292620

Taha, A. E. M. (2018). An IoT Architecture for Assessing Road Safety in Smart Cities. Wireless Communications and Mobile Computing, 2018.

Uzairue, S., Ighalo, J., Matthews, V. O., Nwukor, F. \& Popoola, S. I. (2018). IoT-Enabled Alcohol Detection System for Road Transportation Safety in Smart City. In International Conference on Computational Science and Its Applications, 695-704. Springer, Cham. https://doi.org/10.1007/978-3-319-95171-3_55

Wan Ahmad WM, De Coster R, Wan Ahmad M. (2017). Healthcare Innovation and Performance Factors for Telemedicine Acceptance in Malaysia. ISPIM Innovation Forum: Fostering Innovation Ecosystems, Toronto.
Whitmore, A., Agarwal, A., \& Da Xu, L. (2015). The Internet of Things-A Survey of Topics and Trends. Information Systems Frontiers, 17(2), 261-274. https://doi.org/10.1007/s 10796-014-9489-2

Xu, J., Wang, S., Zhou, A., \& Yang, F. (2020). Edgence: A Blockchain-enabled Edge-computing Platform for Intelligent IoT-based dApps", China Communications, $17(4), 78-87$. https://doi.org/10.23919/JCC.2020.04.008

Yeo KJ., Handayani L., Satria H., Shih-Hui L., \& Yap CK. (2017). Barriers and Challenges to Telecardiology Adoption in Malaysia Context. International Journal of Electrical and Computer Engineering", 7(1), 260.

Zielinski, J. S. (2015). Internet of Everything (IoE) in Smart Grid. Przeglad Elektrotechniczny, 91(3), 157159. https://doi.org/10.15199/48.2015.03.37

\section{司 \\ CHITKARA \\ UNIVERSITY}

Journal of Technology Management for Growing Economies

Chitkara University, Saraswati Kendra, SCO 160-161, Sector 9-C,

Chandigarh, 160009, India

\section{Volume -11, Issue-1}

April 2020

ISSN 2456-3226

Copyright: [C 2020 Inderpreet Kaur and Kamaljit Singh Saini] This is an Open Access article published in Journal of Technology Management for Growing Economies by Chitkara University Publications. It is published with a Creative Commons Attribution- CCBY 4.0 International License. This license permits unrestricted use, distribution, and reproduction in any medium, provided the original author and source are credited. 